\title{
A Subjective Consideration of Agricultural Future Productivity: The Study by a Proposed Model
}

\author{
Tushar Ranjan Sahoo $^{{ }^{*}}$, Saroj Kumar Sahoo ${ }^{1}$ and Biswajit Satpathy ${ }^{1}$ \\ ${ }^{1}$ Post Graduate Department of Business Administration, Sambalpur University,
} Odisha, India.

\section{Authors' contributions}

This work was carried out in collaboration between all authors. Author TRS performed the literature review, wrote the protocol and wrote the first draft of the manuscript. Author SKS structured the research methodology and guided through-out and author BS given initial research intuition and helped to comply the reviews. All authors read and approved the final manuscript.

Article Information

DOI: $10.9734 /$ AJEBA/2017/34261

Editor(s):

(1) Atanu Sengupta, Department of Economics, Burdwan University, West Bengal, India.

Reviewers:

(1) Patil Ranjit Sambhaji, Post Graduate Institute, India. (2) Diana Bílková, University of Economics, Czech Republic. Complete Peer review History: http://www.sciencedomain.org/review-history/19876

Short Research Article

Received 21 $1^{\text {st }}$ May 2017

Accepted $22^{\text {nd }}$ June 2017

Published $5^{\text {th }}$ July 2017

\section{ABSTRACT}

Agriculture is the backbone of Indian economy. Agriculture is not only important in economic point of view but also has subconscious influence on social, political and cultural life. So many researchers have accomplished their study related to the price determinants of agricultural product, but rare researcher worked on 'consumption pattern' as moderated 'price determinants' and 'perception toward future productivity'. By the informal discussion with farmers' it has been judge that there is a great role of farmers' and firm owners' psychology on the future productivity. So, these research issues are addressed in current study that are from the aim of study as follows-

Aim: Aim of study is to find out the relationship between 'price of agriculture product' and its determinants, influence of 'price determination' on 'perception towards future productivity' and the moderation effect of 'consumption pattern' on the relationship between 'price determination' and 'perception towards future productivity' of agricultural products.

Study Design: Descriptive research design applied to study. The relevant literature laid down 
relation between price determinant of agricultural product and future perception of agricultural product.

Methodology: The study based on logical relationships developed through a proposed model. The model refers to moderated mediation effect on the relationship between determinants of price and perception towards future productivity through consumption pattern and price determination of agricultural products. The model has proposed purely based on available literature and the determinants of price are identified from past research works and studies.

Results: Perception towards future productivity is a logical consequence of price determination process, which is influence by various controllable and uncontrollable factors. The consumption pattern acts as moderator between production-perception and price determination process of agriculture products.

Conclusion: Estimating the future production of agricultural products by determinant of price and with the traditional methods is not sufficient in today's dynamic market scenario; the psychological aspect of the future production is a must requirement to estimate the future production, which ultimately becomes the input for planning and strategy.

Keywords: Determinant of price; price determination; consumption pattern; perception towards future productivity.

\section{INTRODUCTION}

Demand and supply considerations of every marketable product are essential in today's competitive market scenario; especially in food products, the importance of demand \& supply is exponential. Not only is the human survival, also their dignity in the society derived from this basic need. The demand of food is increasing day by day whereas the cultivation land is decreasing gradually due to the rapid growth of urbanization and rapid increase in world population. On other hand, farmers are diverting from cultivation to the other occupation, because cultivation is not much profitable in today's business era and price sensitive of Indian customers toward the agriculture products. Farmers are getting losses due to the several factors, such as dependence of Indian cultivation on annual rainfall, timing of monsoon government policy for agricultural inputs and development of infrastructure for cultivation like irrigation facility. By some informal discussions with the farmers and firm owners, it has been judge that some of them are optimistic; some of their pessimistic and others are scared of the government's decisions regarding the helps to farmers. From this result the authors of the study are motivated to conduct a research regarding the psychological aspects of farmers' relating to future productivity. Here, it can be said that there is a great necessity in the today's Indian agricultural scenario to study the farmers' psychological aspects regarding their future plan, instead being driven only by the mechanical considerations or calculative thought like percentage of subsidy, free of cost agricultural material and loan exhumation for enhancing the future productivity. Further, due to irregular in rainfall in India, farmers are facing the drought and the flood in many parts of the nation, which make farmers life miserable. While the amount of family labor applied more for the smaller firm than the amount of wage labor and application of other inputs increases (Sen [1]). The green revolution introduced the high-yielding variety of seeds and fertilizers undoubtedly increased the productivity of land considerably. However, the growth in the productivity has been stagnant in recent years, resulting in a significant decline in the income of farmers. There have also been negative environmental effects in the form of decreasing the ground water, emission of greenhouse gasses, decreasing in annual rainfall, which affect negatively to production the farmer.

Almost two third of India's total population depend on agriculture and the contribution of agriculture to the GDP has been consistently declining. It currently stands at around $15 \%$. A sector that provides work to more than half of the country's population contributing less than $1 / 5^{\text {th }}$ to its GDP indicates a clear imbalance. Agriculture remained more or less stagnant ("Business standard" [2]). Farmers are not getting actual return to its cost of cultivation, due to the incising the cost of inputs (high labour cost, cost of seed and fertilizer), very few agriculture product have MSP (minimum supporting price), value of output decreases of some other product, so in majority cases only $30 \%$ of the consumer rupees comes 
Table 1. Trends in composition of per capita calorie intake by type of food: K. calories/day

\begin{tabular}{lllllllll}
\hline Year & \multicolumn{2}{c}{$\mathbf{1 9 8 7}$} & \multicolumn{2}{c}{$\mathbf{1 9 9 4 - 9 9}$} & \multicolumn{2}{c}{$\mathbf{2 0 0 0 - 0 4}$} & \multicolumn{2}{c}{$\mathbf{2 0 0 5 - 1 0}$} \\
\hline & Calories/day & Share & Calories/day & Share Calories/day & Share Calories/day & Share \\
\hline Other & 100 & $5 \%$ & 124 & $5 \%$ & 134 & $6 \%$ & 148 & $6 \%$ \\
Vegetables \& fruits & 109 & $5 \%$ & 123 & $5 \%$ & 131 & $6 \%$ & 156 & $7 \%$ \\
Meat/Egg/Fish & 28 & $1 \%$ & 30 & $1 \%$ & 31 & $1 \%$ & 35 & $1 \%$ \\
Milk & 99 & $4 \%$ & 106 & $5 \%$ & 96 & $4 \%$ & 105 & $5 \%$ \\
Vegetable oils & 147 & $7 \%$ & 179 & $8 \%$ & 184 & $8 \%$ & 204 & $9 \%$ \\
Sugar & 183 & $8 \%$ & 198 & $9 \%$ & 207 & $9 \%$ & 200 & $9 \%$ \\
Pulses & 120 & $5 \%$ & 115 & $5 \%$ & 106 & $5 \%$ & 112 & $5 \%$ \\
Cereals & 1459 & $65 \%$ & 1407 & $62 \%$ & 1367 & $61 \%$ & 1351 & $58 \%$ \\
\hline
\end{tabular}

to farmer (Narayanamoorthy [3]). The above aspects justify poor planning \& strategy in the agricultural sector of India, especially of the rural economy of India, where the lively-hood of the farmer is much lesser to sustain in their occupation. The consumption pattern suggested to be a moderating role towards the future productivity, not directly influencing the future productivity. Had the consumption pattern been directly influencing the future productivity, it would be increasing according to the increase of the consumption pattern. But this is not the case, so far as above mention statics (Table 1 above) [4] is concern. Here the overall production of agricultural product is increasing (though not according to increase in population), even if the cereals and pulses decreases. If the milk, meat, fish, vegetable and fruits will be considered, it is seen that the consumption pattern of a above said product are increasing even with the increase of price. Further, from the bellow mentioned statistics it is infer that the consumption pattern of cereals in India is decreasing gradually from year 1987-2010, and consumption pattern of pulses overall decreasing, whereas the consumption pattern of vegetable and fruits, meat, egg, fish, milk and vegetable oils are increasing. Therefore, it is important to study the firms and farmers' perception towards the future productivity.

\section{PROBLEM STATEMENT}

Agriculture is the lifeline of the Indian economy, where both the problems and prospects of agriculture sector are complex in nature. Keeping in view the above aspect as the ground of decision-making, the planners and strategists need to think seriously regarding the future prospects of agricultural outputs. In this context, a study regarding the perception of firms and farmers towards future productivity can give the guidelines to those planners and strategist. Further, the Indian consumers are price sensitive in nature, especially visible in agricultural products, which make the planners' work more complex. Thus, the problem statement of the current study refers that "can the perception towards future productive of agricultural products be studied with respect to their price and the antecedents of price"?

\subsection{Objectives of Study}

1. To study the logical relationship between the price of agricultural products and its determinants.

2. To analyze the influence of 'price determination' on 'perception towards future productivity' of agricultural products.

3. To propose the moderation effect of 'consumption pattern' on the relationship between 'price determination' and 'perception towards future productivity' of agricultural products.

\section{METHODOLOGY}

This study follows the descriptive research design, where logical relationships developed through a proposed model. The model refers to moderated mediation effect on the relationship between determinants of price and perception towards future productivity through consumption pattern and price determination of agricultural products. The model proposed in the current study is based on available literature. The determinants of price are identified from past research works and studies. Moreover, based on the logical explanations, future research avenues and limitations of those research works, the price determination of agricultural products becomes mediator and consumption pattern becomes the moderator in the model. The first author observed many situations where different determinants of the price of agricultural product influence pricing process, while acted as an executive in a PACS (primary agricultural 
cooperative society). Some informal discussion conducted with the farmers and the firm owners to know their thought process (planning) regarding the future productivity of the concern agriculture product. This practical experience contributed a lot to the logic of relating the perception of farmers towards the future productivity with pricing process.

\section{RESULTS AND DISCUSSION}

Relating to various literatures, a model is suggested, which shows that the price determination process of agriculture products leads to perception towards future productivity. The logical relationships of controllable and uncontrollable determinants of price are taken in to consideration for the above said perception. Consumption pattern is playing an important role for both the price determination and perception towards future productivity.

\subsection{Determinants and Determination of Price}

To justify the objectives of the study an analytical framework is proposed for Indian scenario, where the price determination process for the agriculture produces can be accomplished by some determinants and then this price determination leads to the perception towards future productivity. On the view of planning or strategy, three determinants can be considered as controllable and rest of the three are uncontrollable in nature to justify the proposed model (Fig. 1). The controllable determinants are present stock and availability, the cost of agricultural inputs and technological changes in the agricultural product. The uncontrollable variables are the future demand of the agriculture product; unanticipated environmental changes and the overall economy of the country. The consumption pattern is proposed to be a moderator, which build the perception in either way regarding the future productivity, upholding itself unchanged.

\subsection{Relationship between Controllable Variables and Price Determination}

With the planners' point of consideration, a study result is meaningful here that a policy, which integrates stock and trade operation can help to achieve the longer objective of domestic price stability even in volatility of international and domestic output. Further, any government policy can be successful by doing the stock operations at the market-determined price (Dev \& Zhong [5]). So, it can be said that stock of food grain has an important role for maintaining the price stability of agriculture products. In this context, another researcher refers that stock of rice and wheat maintained by the Government of India to meet the requirement of public distribution system and for open market sales in the aim of reducing price fluctuation. Further, the same study referred that these stocks are mainly buildup through the price support system and sometimes import route used for maintaining the stock (Acharya [6]). If it will be a discussion of fruit and vegetable, then the result of a study is worthy here that fruit and vegetable lack of inadequate scientific storage and other facilities, which cause heavy losses in terms of huge wastage of quality and quantity of crops, ultimately leading to seasonal fluctuation in price. Further, few food processing units add the value to the crop and reduce the loss of farmers in India (Huka, Ruoja, \& Mchopa [7]). Losses faced by farmer and price instability of fruits and vegetable are huge because the government contribution to maintain the stock is very less and the perishable nature of these products is making situation more complex.

Narayanamoorthy [3] found that profit earned by farmers in major cases is less than one third cost of cultivation. The causes of losses are due to the cost of cultivation and reduced value of output of other products. Here the author suggested that solution of the present agricultural crisis should be the price fixation of crop with respect to the cost of cultivation. Further, it needed to link some crop to minimum supporting price announced every year for protect the farmer from the possible inflammatory pressure of wholesale price index. The price of input gradually incising but the agricultural output price is not increasing accordingly, so farmers are facing losses. Government is announcing the minimum supporting price only in few crop only majority cases it fails. Therefore, farmers are fell ineptness in their profession. Moreover, another author addressed 'the major factors of ineptness of farmers' is instability of food grain yield, rising cost of cultivation and diminishing net return comes from cultivaton. With the commercialisation of agriculture, the ineptness increased because the commercial credit and low return increased (Sajjad \& Chauhan [8]). By examining facts, researcher coined that cost of cultivation and futile price fixation policy major cause of ineptness, credit burden and losses face by farmers. 


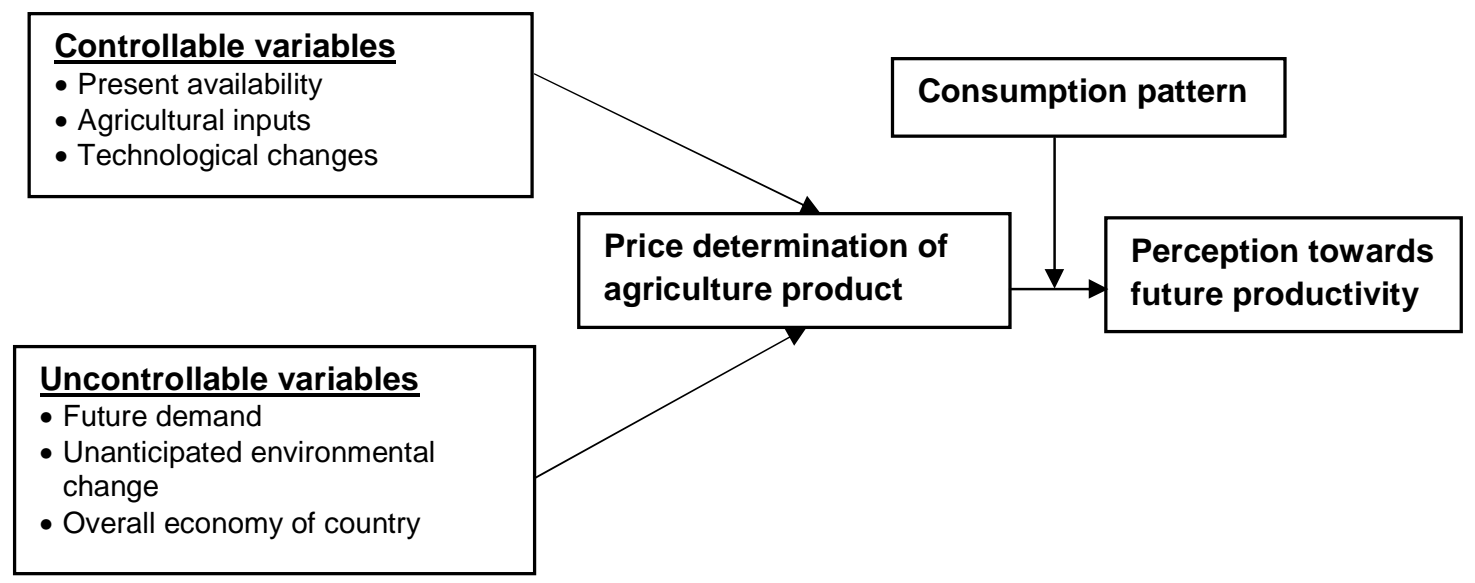

Fig. 1. Proposed model: Perception towards future productivity goes with price determination process

With many years of green revolution, India is still facing agricultural crises. To eliminate such problem there must be collaboration between green revolution, information and communication revolution. In addition, there is needed the training, re-training, redeployment of both the farmer and farm graduate and firm graduate must involve in the agriculture activity in rural area and co-operation with the rural farmer. So rural area must generate the urban style employment and help checking the rural - urban mitigation (Joshi [9]). Therefore, the rural farmers will get updated information, skill and technology regarding agronomy. Again, another researcher's consideration Green revolution and technology implication in Indian agriculture prevent the famines and reduced the poverty level Haryana and Punjab like states. So its effect on overall economy should not consider because it somehow reduce the poverty (Panning \& Kulkarni [10]). Both above authors found that technology implication increase the productivity but it is not sufficient and there is a need of collaboration of communication technology with the agricultural technology.

\subsection{Relationship between Uncontrollable Variables and Price Determination}

In the recent trends in production, meeting future demand for food grains through domestic production alone appears to be difficult, but not impossible. It is most necessary to improve the production and expansion of the agricultural land. Further, according to planners' consideration,to meet the food grain demand in 2011-12, the yields of different commodities must be raised to a minimum of $2.37 \mathrm{t} / \mathrm{ha}$ for rice, $3.07 \mathrm{t} / \mathrm{ha}$ for wheat, and $0.68 \mathrm{t} / \mathrm{ha}$ for pulses. By 2021-22, yields must further be improved to $2.65 \mathrm{t} / \mathrm{ha}$ for rice, $3.38 \mathrm{t} / \mathrm{ha}$ for wheat and $0.85 \mathrm{t} / \mathrm{ha}$ for pulses (Kumar, Joshi, \& Birthal [11]). As per the above statics, the demand of the agriculture will be very high in future, which leads to bright future of framer in their profession. Another study indicated that in China and India per-capita consumption of food will continue to grow because of rapid growth of economy and rapid urbanization. Further, the study made a projection that by 2050 food require for India will be double to the China (Webeck, Matsubae, \& Nagasaka [12]), which shows that there is better opportunity for the Indian farmers with respect to pricing decisions.

Mall, Singh, Gupta, Srinivasan, \& Rathore [13] given few important results regarding Indian agriculture sector that the impacts of climate change on Indian agriculture are uncertain and the total average impact may be positive or negative depending on the climate of that area. Further, impacts also vary both quantitatively and qualitatively with respect to crop, level of agronomic management, region and season. However, most scenarios show that climate change will have an overall positive impact or not affect significantly on India's agriculture until mid of the twenty first century but around end of twenty first century temperature will increase significantly at high rate, for which Indian agriculture will suffer the most. Again, Mall et al. [13] said that food production is not threatened up to mid of the twenty first century and does not need to import food, but around end of twenty first century food production will have threatened. 
So, the farmers' recent future will not affected by any climatic change but still in some case farmers are facing problem due to the climatic change. Bahinipati \& Patnaik [14] also propounded that for every $1 \%$ increase in the agricultural dependent population, $0.02 \%$ is likely to suffer due to these climatic extremes, which is very negligible and can be ignore due to the bulk production. Above discussions pointing out that the climate change will not affect much to the future agriculture production. Hence, pricing uncertainty will not be visible for the agriculture product and farmers will not be panic with respect to their future production.

Services sector is the largest sector of India. Gross Value Added (GVA) at current prices for services sector is estimated at 73.79 lakh crore INR in 2016-17. Services sector accounts for $53.66 \%$ of total India's GVA of 137.51 lakh crore Indian rupees. With GVA of Rs.39.90 lakh crore, Industry sector contributes $29.02 \%$. While, Agriculture and allied sector shares $17.32 \%$ and GVA is around of 23.82 lakh crore INR. Further, the contribution of agricultural to GDP at net value still incising, as statics shows that the net value, $1,501,816$ crore INR contribute to the Indian GDP in the year 2011-12 and it is gradually increasing up to the year 2016-2017, where it contributes $2,382,289$ crore INR to the GDP of India ("Statistics times," [15]). This shows that the share of agricultural contribution to GDP decresing but still the net vale of agricultural output is increasing. As over all economy is increasing, a huge opportunity is there for the agricultural product in India, which ultimately open the opportunities for farmers' income in an optimism way. Again, Wagh \& Dongre, [16] found that growth of the agricultural sector depends on multiple factors that are working together, where these factors include income and consumption, expansion of food processing sectors and increasing in the agriculture exports. Also rising in private participation in Indian agriculture, growing organic farming and use of the information technology are some of the key trends of agriculture industry, which shows that the growing trend of economy with respect to the agriculture sector is giving a positive signal to the indian famers for the future production. As per the bellow mentioned table (Table 2) [15] contribution to GDP by agiculture, and agriculture and allied sectctor decreses overally where as industry and service sector increse overall. These statistics refers that the psychology of farmers are influenced by the current trends of consumption pattern, ultimately shaping their perception towards future production.

Table 2. Contribution to GDP from major sectors

\begin{tabular}{lllll}
\hline Year & Agriculture & Agriculture and allied & Industry & Service \\
\hline $1990-91$ & 24.65 & 29.02 & 26.49 & 44.18 \\
$1991-92$ & 25.16 & 29.39 & 25.4 & 44.96 \\
$1992-93$ & 24.56 & 28.74 & 25.77 & 45.22 \\
$1993-94$ & 24.46 & 28.68 & 25.5 & 45.57 \\
$1994-95$ & 24.08 & 28.27 & 26.41 & 45.03 \\
$1995-96$ & 22.39 & 26.26 & 27.4 & 46.05 \\
$1996-97$ & 23.25 & 27.13 & 26.6 & 45.96 \\
$1997-98$ & 21.98 & 25.89 & 26.41 & 47.45 \\
$1998-99$ & 22.04 & 25.79 & 25.74 & 48.26 \\
$1999-2 K$ & 20.96 & 24.5 & 25.22 & 50.27 \\
$2000-01$ & 19.43 & 23.02 & 26 & 50.98 \\
$2001-02$ & 19.34 & 22.92 & 25.08 & 51.99 \\
$2002-03$ & 17.26 & 20.7 & 26.17 & 53.13 \\
$2003-04$ & 17.49 & 20.74 & 26.01 & 53.25 \\
$2004-05$ & 16.04 & 19.03 & 27.93 & 53.05 \\
$2005-06$ & 15.83 & 18.81 & 28.13 & 53.06 \\
$2006-07$ & 15.3 & 18.29 & 28.84 & 52.87 \\
$2007-08$ & 15.63 & 18.26 & 29.03 & 52.71 \\
$2008-09$ & 15.21 & 17.78 & 28.29 & 53.93 \\
$2009-10$ & 15.2 & 17.74 & 27.76 & 54.5 \\
$2010-11$ & 15.78 & 18.21 & 27.16 & 54.64 \\
$2011-12$ & 15.5 & 17.86 & 27.22 & 54.91 \\
$2012-13$ & 15.1 & 17.52 & 26.21 & 56.27 \\
$2013-14$ & 15.79 & 18.2 & 24.77 & 57.03 \\
\hline
\end{tabular}

Source: Statistical times (21 Mar. 2017) 


\subsection{Moderation Effect of Consumption Pattern on the Relationship between Future Productivity and Price Determination}

There has been a switch in preferences towards non-cereal items, such as meat/fish/eggs and fruits/vegetables. Irrespective of causes of these changes, a significant decline in calorie consumption transpired due to the switch-over from calorie intensive cereal items to non-cereals which are more expensive sources of calories (Golait \& Pradhan [17]). So, by financially healthy people are preferring calorie intensive noncereal food like fruits and vegetable, egg, meat rather than the cereal food like wheat and rice. In this context, Anand [18] found that faster urbanization backed by deskbound lifestyles, rising dual incomes, growing wealth, and independence of young people in modern societies have been driving a gradual change in the consumption pattern. Another finding of Anand [18] is worth mentioning here to prove the moderation effect of consumption pattern mentioned in the current study as influence of globalization also visible in the production and processing of food as well as its sales, preparations and consumption. Consumers around the world now finding in supermarkets the same food products that are produced by the same producer and prefer the processed of semi processed food to parches. It indicates that consumption pattern has also some impact on the food price and the productionperception.

\section{SUMMERY FINDINGS}

The agricultural product marketing in Indian scenario is so crucial and complex that, the psychological factors of firms and farmers need to be understood by any planners or strategists clearly. Further, most of the psychological factors relating to agriculture products in Indian scenario become more complex, if it is a matter of price of those products. In this context, a simplified model will be very much helpful for planners and strategists. The current study proposed a model where the production-perception is a logical consequence of price determination process and the price determination process is influenced by various relevant factors in Indian scenario.

As an estimation of future productivity is very important for any planning and strategy relating to the agricultural product, so many objective oriented estimation of future productivity have been established by numerous researcher till today but the subjectivity in Indian scenario relation to the future productivity is very important to be study as suggested in the model of current study. Here the perception toward future productivity, a subsequent consideration, of firms' and farmers' is the consequence of price determination of the agriculture product, being moderate by the consumption pattern. The degree of fluctuations of consumption pattern of a particular market brings changes in perception towards the future productivity, while it is directly judged by price determination process. Therefore, the consumption pattern does not change by itself, but bring change in productionperception. Thus, consumption pattern act as a moderator.

The price determination of agriculture product is not constant and certain in every time over all the products. So, the price determination is considered as a process, specific to the product, time and market. For this reason, some controllable and uncontrollable variables must be considered for the price determination process of agricultural products. Here the controllable variables are present availability, agricultural inputs and technological changes and uncontrollable variables refer to future demand, unanticipated environmental change and overall economy of country. So, it can be logically understood that by exploiting price determination process, the planners and strategists can assess in better way the firms' or farmers' perception towards future productivity.

\section{CONCLUSION}

Effective marketing and distribution of agricultural products are such an important aspect in India that the growing population size and their demand may spread chaos, if not taken care in right time. In this conjecture, the planners and strategists play a vital role to manage or to take the timely steps for effective marketing and distribution of agricultural products. The current study can contribute an important piece of knowledge to those planners and strategies by revealing the logical relationship between the price determination process and perception towards the future productivity of firms and farmers, because knowledge regarding future productivity is the most important tool to formulate the plans and strategies regarding agriculture product. In Indian scenario, the future 
productivity is governed indirectly but strongly by the psychology of producers. Thus, both the controllable and uncontrollable variables are considered as the determinants of price of agriculture products and ultimately of future productivity. The current study proposed that the production- perception can be assessed by price determination and with the help of 'consumption pattern' of the concerned market, which is shown as the moderator in the proposed model. Therefore, planners and strategist should estimate the future production not only by traditional demand forecasting methods but also by considering the psychological aspects of the producer for the better strategy and planning.

\section{LIMITATION OF STUDY}

The study is based uponreview of published studies, surveys, and news articles, where a model has been proposed by applying the logical relationships. But the empirical justification can be more application oriented. The proposed model is addressing some determinant price, which are relevant in present economic and market scenario of India. The future studies may consider some of determinants as no more relevant because of the dynamism of the consumption pattern. The price-sensitive of Indian consumers differs according to products. So, the relationship between price determination and perception towards future productivity may not be moderated by 'consumption pattern' for other products rather than agricultural products. So, for the other products the model can be reoriented.

\section{COMPETING INTERESTS}

Authors have declared that no competing interests exist.

\section{REFERENCES}

1. Sen AK. An aspect of Indian agriculture. The Economic Weekly. 1962;243-6.

2. Anonymous. Future of agriculture in India: Is the nation ready? Business Standard News. Business standard; 2016.

(Accessed 4 Jun 2017)

Available:http://www.businessstandard.com/content/b2bchemicals/future-of-agriculture-in-india-isthe-nation-ready-116053000558 1.htmls

3. Narayanamoorthy A. Profitability in crops cultivation in India: Some evidence from cost of cultivation survey data. Indian $\mathrm{J}$ Agric Econ. 2013;68(1):104-121.

4. National Council of Applied Economic Research. An analysis of changing food consumption pattern in India. Parisila Bhawan, 11, I.P Estate, New Delhi; 2014.

5. Dev SM, Zhong F. Trade and stock management to achieve national food security in India and China? China Agric Econ Rev. 2015;7(4):641-54.

6. Acharya SS. Food security and Indian agriculture: Policies, production performance and marketing environment. Agric Econ Res Rev. 2009;22(1):1-19.

7. Huka H, Ruoja C, Mchopa A. Price fluctuation of agricultural products and its impact on small scale Farmers Development: Case analysis from Kilimanjaro Tanzania. Eur J Bus Manag. 2014;6(36):155-61.

8. Sajjad H, Chauhan C. Agrarian distress and indebtedness in rural India: Emerging perspectives and challenges ahead. J Geogr Reg Plan. 2012;5(15):397-408.

9. Joshi S. Role of science and technology for agricultural revival in India. World J Sci Technol Sustain Dev. 2012;9(2):108-19.

10. Panning A, Kulkarni KG. Technology for growth: Indian green revolution. SCMS J Indian Manag. 2011;49-63.

11. Kumar P, Joshi PK, Birthal PS. Demand projections for food grains in India. Agric Econ Res. 2009;22:237-43.

12. Webeck E, Matsubae K, Nagasaka T. Phosphorus requirements for the changing diets of China, India and Japan. Environ Econ Policy Stud. 2015;17(3):455-69.

13. Mall RK, Singh R, Gupta A, Srinivasan G, Rathore LS. Impact of climate change on Indian agriculture: A review. Clim Change. 2006;78(2-4):445-78.

14. Bahinipati CS, Patnaik U. The damages from climatic extremes in India: Do disaster-specific and generic adaptation measures matter? Environ Econ Policy Stud. 2015;17(1):157-77.

15. Anonymous.Sector-wise contribution of GDP of India - StatisticsTimes.com. March $21 ; 2017$.

(Accessed 4 Jun 2017)

Available:http://statisticstimes.com/econom y/sectorwise-gdp-contribution-of-india.php

16. Wagh R, Dongre AP. Agricultural sector: Status, challenges and it's role in Indian economy. J Commer Manag Thought. 2016;7(2):209-18. 
17. Golait R, Pradhan NC. Changing food consumption pattern in Rural India: Implication on food and nutrition security. Ind Jn Agri Econ. 2006;61(3):374-388.
18. Anand R. A study of determinants impacting consumers food choice with reference to the fast food consumption in India. Soc Bus Rev. 2011;6(2):176-87.

(c) 2017 Sahoo et al.; This is an Open Access article distributed under the terms of the Creative Commons Attribution License (http://creativecommons.org/licenses/by/4.0), which permits unrestricted use, distribution, and reproduction in any medium, provided the original work is properly cited.

Peer-review history:

The peer review history for this paper can be accessed here: http://sciencedomain.org/review-history/19876 